ISSN 1598-0170 (Print)

ISSN 2287-1136 (Online)

http://www.jksii.or.kr

\title{
$\mathrm{BPM}$ 기반의 업무수행자 대응분석 기법놔
}

\section{A BPM Activity-Performer Correspondence Analysis Method}

\author{
안 현1 \\ Hyun Ahn
}

박 천 건2

Chungun Park
김 광 훈 ${ }^{*}$

Kwanghoon Kim

\section{요 약}

비즈니스 프로세스 인텔리전스(BPI)는 지식의 발견 및 분석 분야의 새로운 기술로서, BPM 기반 조직에 관련된 지식을 발견하고 이를 분석하기 위한 기술들을 말한다. BPI를 통해, 프로세스 기반 조직의 지식을 제어, 모니터링, 예측, 최적화할 수 있게 되는데, 본 논문에서는 특정 비즈니스 프로세스 모델에 참여하는 수행자들과 업무들간의 소속 관계를 나타내는 BPM 업무-수행자 소속성 네트워 크 지식에 초점을 맞춘다. 즉, 본 논문에서는 BPM 업무-수행자 소속성 네트워크 지식을 위한 통계 분석 기법을 제안하며, 이를 업무수행자 대응 분석 기법이라 정의한다. 제안하는 대응 분석 기법의 과정은 이분 행렬을 생성하고, 이에 대한 대응 분석 결과를 가시화 하는 과정으로 구성되며, 이를 통해 비즈니스 프로세스 모델 또는 비즈니스 프로세스 패키지에 소속되는 수행자 그룹과 업무 그룹간 의 연관 관계를 분석할 수 있다. 결론적으로, 제안하는 업무-수행자 대응 분석 기법을 통해 BPM 기반 조직을 위한 비즈니스 프로세스 모델 또는 비즈니스 프로세스 패키지의 계획 및 설계 과정에서, 업무와 수행자간의 연관 관계를 고려하여, 인적 자원 할당의 효과성 과 효율성을 제고할 것이라 기대된다.

주제어 : 비즈니스 프로세스 인텔리전스; 소속성 네트워크; 대응분석

\section{ABSTRACT}

Business Process Intelligence (BPI) is one of the emerging technologies in the knowledge discovery and analysis area. BPI deals with a series of techniques from discovering knowledge to analyzing the discovered knowledge in BPM-supported organizations. By means of the BPI technology, we are able to provide the full functionality of control, monitoring, prediction, and optimization of process-supported organizational knowledge. Particularly, we focus on the focal organizational knowledge, which is so-called the BPM activity-performer affiliation networking knowledge that represents the affiliated relationships between performers and activities in enacting a specific business process model. That is, in this paper we devise a statistical analysis method to be applied to the BPM activity-performer affiliation networking knowledge, and dubbed it the activity-performer correspondence analysis method. The devised method consists of a series of pipelined phases from the generation of a bipartite matrix to the visualization of the analysis result, and through the method we are eventually able to analyze the degree of correspondences between a group of performers and a group of activities involved in a business process model or a package of business process models. Conclusively, we strongly expect the effectiveness and efficiency of the human resources allotments, and the improvement of the correlational degree between business activities and performers, in planning and designing business process models and packages for the BPM-supported organization, through the activity-performer correspondence analysis method.

F keyword : Business Process Intelligence; Affiliation Network; Correspondence Analysis

\section{1. 서 론}

비즈니스 프로세스 관리 시스템(Business Process Management

1 Department of Computer Science, Kyonggi University, Gyeonggi-do, 443-760, Korea

2 Department of Mathematics, Kyonggi University, Gyeonggi-do, 443-760, Korea

* Corresponding author (kwang@kgu.ac.kr)

[Received 16 May 2013, Reviewed 21 May 2013, Accepted 27 July 2013]

눈 본 논문은 중소기업청에서 지원하는 2013년도 산학연공동기술 개발사업(No. 2013-0625)의 연구수행으로 인한 결과물임을 밝힙니다.
System, BPMS)은 조직에서 운용되는 비즈니스 프로세스 의 정의, 실행, 모니터링, 분석, 최적화의 과정으로 반복 되는 수명 주기(business process lifecycle)를 관리하기 위 한 가장 효과적인 프로세스 기반 정보 시스템으로서, 최 근 여러 산업 방면의 조직에서의 적용사례가 증가하고 있다. 이러한 BPMS는 일반적으로 비즈니스 프로세스 실 행을 자동화하기 위한 워크플로우 중심의 프로세스 자동 화 기술[1,2]과 웹서비스를 기반으로 하는 프로세스 협업 
기술, 그리고 비즈니스 프로세스 실행에서 호출되는 다양 한 엔터프라이즈 응용 프로그램들을 통합하기 위한 EAI (Enterprise Applications Integration)기술 등을 포함하는데 [3,4], 최근에는 경영 환경의 빠른 변화에 따라, 단일 조직 이 아닌 여러 조직간의 업무 협업을 위한 대규모 비즈니 스 프로세스의 운용이 요구되는 경우가 빈번하며, 이에 투입되는 자원(인적 자원, 데이터베이스, 응용 프로그램 등)규모 또한 비약적으로 증가함에 따라 복잡해진 비즈 니스 프로세스의 품질 관리를 위한 다양한 비즈니스 프 로세스 분석 기술이 등장하게 되었다[5-10].

비즈니스 프로세스 인텔리전스(business process intelligence, $\mathrm{BPI}$ 는 비즈니스 프로세스 모델 또는 실행 이력으로부터 데이터를 수집하고 다양한 분석 과정을 통해 비즈니스 프로세스의 품질 개선 또는 조직의 비즈니스 의사 결정 을 위한 유용한 정보를 제공하기 위한 분석 활동 또는 이 를 지원하는 응용 프로그램들의 집합으로 정의된다 $[8,9]$. 하지만 대부분의 BPI 연구들이 비즈니스 프로세스에 대 한 분석이 업무, 제어흐름 관점에 한정된 경우가 많았으 며, 실질적으로 업무를 수행하는 인적 자원에 대한 높은 수준의 정보를 효과적으로 획득하기가 쉽지 않았다. 비즈 니스 프로세스에 할당되는 인적 자원은 업무를 수행하는 실질적인 주체로서, 업무에 가장 적합한 인적 자원의 할 당 및 인적 자원 그룹내의 형성될 수 있는 업무 협업 관 계 등에 따라 비즈니스 프로세스 수행의 전체적인 성능에 큰 영향을 미칠 수 있다. 그러므로 기존 비즈니스 프로세 스의 최적화, 또는 새로운 비즈니스 프로세스 설계의 효 율성을 제고하기 위해서는 비즈니스 프로세스에 할당되 는 인적 자원에 대한 효과적인 분석이 반드시 필요하다.

이에 본 논문에서는 이벤트와 사람간의 연결 관계를 나타내는 소속성 네트워크(affiliation network)[11,12]의 개 념을 비즈니스 프로세스에 적용한 업무-수행자 소속성 네트워크[13-15]를 대상으로 대응분석을 실시하여 BPM (Business Process Management)기반 조직의 업무와 수행자 간의 연관 관계를 분석하고자 한다. 대응분석은 다변량 통계 분석 기법중 하나로서, 서로 다른 차원의 자료들간 의 상호 연관성을 2 차원 평면의 형태로 요약하여 가시화 하는 탐색적 자료 분석 방법이다[16]. 일반적으로 이원 분할표의 자료를 대상으로 분석을 실시하지만, 본 논문 에서는 BPM 기반 조직의 업무-수행자 대응분석 기법을 다루므로, 업무-수행자 소속성 네트워크를 나타내는 업 무-수행자 이분 행렬[15]의 자료를 대상으로 분석을 실시 한다. 그러므로 본 논문의 대응분석 과정은 $\mathrm{BPMS}$ 에서 운용되는 비즈니스 프로세스 모델의 정의로부터 업무와
수행자간의 연결 관계를 나타내는 업무-수행자 소속성 네트워크 모델의 발견 과정과 이것에 대한 업무-수행자 이분 행렬을 생성하는 과정, 마지막으로 생성된 업무-수 행자 이분 행렬을 대상으로 대응분석을 실시하는 과정으 로 이루어진다.

결론적으로 본 논문에서 제안하는 BPM 기반의 업무수행자 대응분석 기법을 통해 업무와 수행자간 소속 관 계, 수행자간의 업무 협업 관계, 업무간의 수행자 공유 관계에 대한 종합적인 정보를 가시화된 2차원 평면을 통 해 탐색적으로 살펴볼 수 있다. 이러한 분석 결과는 BPI 에서 요구되는 기능인 효과적인 비즈니스 프로세스 설계 를 가능하게 하며, 구체적으로 BPM 기반 조직의 업무와 수행자간의 연관 관계를 고려한 비즈니스 프로세스 설계 에 도움이 될 수 있다.

본 논문은 다음과 같이 구성된다. 2장에서는 BPI의 개 념과 이에 관련된 선행 연구들에 대해서 소개하며, 3 장에 서는 본 논문의 분석 대상인 업무-수행자 소속성 네트워 크 모델과 이의 발견 과정에 대해서 서술한다. 4 장에서는 본 논문에서 제안하는 BPM 기반의 업무-수행자 대응분 석 기법에 대해서 기술하며, 마지막으로 5 장에서는 결론 및 향후 연구에 대해 설명한다.

\section{2. 관련 연구}

BPI는 비즈니스 프로세스를 대상으로 하는 비즈니스 인텔리전스(business intelligence) 활동 또는 이를 지원하 는 기술로 정의할 수 있다. 즉, 비즈니스 프로세스의 모 델 또는 실행 이력으로부터 비즈니스 프로세스 관련 데 이터를 수집하고 분석 과정을 통해 비즈니스 프로세스를 예측, 감시, 제어, 최적화하여 비즈니스 프로세스의 실행 품질을 개선하며, 더 나아가 조직의 비즈니스 의사 결정 을 지원하는 것을 목적으로 한다[8,9].

D. Grigori, et al.[8]에서는 BPI의 개념을 비즈니스 프 로세스의 실행 품질을 관리하기 위해 비즈니스 프로세스 의 분석, 예측, 감시, 제어, 최적화를 지원하는 도구로 정 의하였다. 또한 Hewlett-Packard사의 BPMS인 HP Process Manager(HPPM)의 실행 로그 데이터로부터 BPI 활동을 지원하기 위한 시스템 아키텍처를 제안하였다. 이와 비 슷하게 J. Schiefer, et al.[9]에서는 비즈니스 프로세스를 감시하고, 지속적으로 개선하기 위해 실시간으로 실행 로그 데이터를 분석하여 프로세스의 실행 성능 데이터를 생성하고, 프로세스 웨어하우스(warehouse)를 구축하여 프로세스 기반 의사결정 시스템을 지원하기 위한 BPI 아 
키텍처를 제안하였다.

$\mathrm{BPI}$ 를 위한 시스템 아키텍처 외에도 이를 실현하기 하기 위한 비즈니스 프로세스 분석 기법에 대한 연구들 이 선행되었다[5-7,10]. W. Tan, et al.[10]에서는 동적으로 비즈니스 프로세스의 성능을 측정하기 위한 측정 모델과 성능 평가 방법론을 제안하였다. 측정 모델은 비즈니스 프로세스를 여섯 가지 관점(activity, information, resources, cost, cash, profit)의 흐름으로 정의하며, 이에 대한 다양한 성능 평가 기준을 통해 비즈니스 프로세스의 성능을 동 적으로 측정하여, 프로세스 분석 및 예측의 효율성을 높 이고자 하였다.

[5]에서는 비즈니스 프로세스의 실행 로그 데이터로부 터 비즈니스 프로세스 모델을 재발견하기 위한 마이닝 기 법을 제안하였으며, 이러한 개념을 프로세스 마이닝이라 정의하였다. [6,7]에서 제안한 워크플로우 발견 및 재발견 을 위한 분석 기법 또한 워크플로우 모델 및 로그 데이터 로부터 워크플로우 관련 지식을 발견하기 위한 프로세스 마이닝 기법으로서 $\mathrm{BPI}$ 와 밀접하게 연관되어 있다. 그러나 앞서 설명한 프로세스 마이닝 관련 연구들은 비즈니스 프 로세스의 분석 범위가 제어 흐름(업무 흐름)에 제한되어, 한정된 지식만을 발견할 수 있으며, 특히 업무를 수행하는 인적자원 관련 지식을 효과적으로 발견하기 쉽지 않았다.

최근에는 비즈니스 프로세스를 조직 관점으로 분석하 여 비즈니스 프로세스를 수행하는 인적자원 그룹내에서 형성되는 소셜 네트워크를 분석하기 위한 연구들이 선행 되었다[13-15,17,18]. 특히 [13,14]에서는 이벤트(event)와 수행자(actor)의 관계를 나타내는 소속성 네트워크의 개 념을 워크플로우에 적용하여 이를 워크플로우 기반 소속 성 네트워크라 정의하였으며, 워크플로우 모델로부터 이 를 발견하기 위한 알고리즘을 제안하였다. 즉, 워크플로 우 기반 소속성 네트워크는 워크플로우 또는 BPM 기반 조직의 업무와 수행자간의 소속 관계를 나타내며 본 논 문은 [13-15]의 워크플로우 기반 소속성 네트워크에 대응 분석을 하기 위한 기법을 제안함으로써 업무와 인적자원 간의 연관 관계를 고려한 비즈니스 프로세스 설계의 효 율성을 높이고자 한다.

\section{3. 업무-수행자 소속성 네트워크 모델}

본 장에서는 BPM 기반 업무-수행자 대응분석의 입력 형태인 업무-수행자 소속성 네트워크 모델과 이에 대한 배경 이론으로서 비즈니스 프로세스를 정형적, 가시적으 로 정의하기 위한 명세 방법인 ICN(Information Control $\mathrm{Net}$ )에 대하여 설명한다.

\section{$3.1 \mathrm{ICN}$ 워크플로우 모델}

$\mathrm{ICN}$ 은 워크플로우 모델을 정형적 또는 가시적으로 정 의하기 위한 전통적인 명세 방법이며[19], 비즈니스 프로 세스 또한 워크플로우와 동일한 개념으로서 $\mathrm{ICN}$ 을 통해 정의될 수 있다. (그림 1)는 워크플로우를 구성하는 기본 엔티티 유형과 이들간의 상호 관계를 나타내는 워크플로 우 메타 모델이며, ICN 워크플로우 모델은 이러한 메타 모델을 기반으로 정의된다.

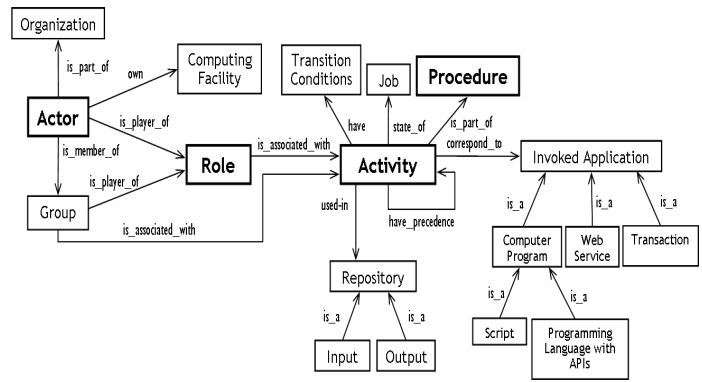

(그림 1) 워크플로우 메타 모델

(Figure 1) The workflow meta-model

워크플로우 메타 모델의 기본 엔티티들은 워크플로우 프로시저(비즈니스 프로세스), 단위 업무(activity) 역할, 수행자, 연관 데이터, 전이 조건, 호출 프로그램 등이 있 다. 그러므로 (그림 1)의 워크플로우 메타 모델을 바탕으 로 $\mathrm{ICN}$ 워크플로우 모델을 $\Gamma=(\delta, \rho, \gamma, \lambda, \epsilon, \pi, \kappa, \mathbf{I}$, O)와 같이 정형적으로 표현할 수 있으며, 각각의 튜플에 대한 의미는 [19]에 정의되어 있다. 본 논문에서의 분석 대상인 업무-수행자 소속성 네트워크 모델은 이러한 ICN 워크플로우 모델의 정형적 정의에서 정의 1 과 같이 단위 업무와 조직 단위(역할, 수행자)와의 할당 정보를 나타내 는 조직 관점의 ICN 워크플로우 모델로부터 발견할 수 있다. 여기서 $\mathbf{A}$ 는 단위 업무들의 집합이며, $\mathbf{R}$ 은 역할들 의 집합, $\mathbf{P}$ 는 수행자들의 집합을 나타낸다.

[정의 1] 조직 관점의 $\mathrm{ICN}$ 워크플로우 모델 정의 $\Gamma_{\mathbf{R}}=$ [ function $(\epsilon, \pi), \operatorname{set}(\mathbf{A}, \mathbf{R}, \mathbf{P})]$

- 단위 업무들의 집합, $\mathbf{A}=\left\{\alpha_{1}, \ldots, \alpha_{n}\right\}$;

- 역할들의 집합, $\mathbf{R}=\left\{v_{1}, \ldots, v_{m}\right\}$;

- 수행자들의 집합, $\mathbf{P}=\left\{\phi_{1}, \ldots, \phi_{k}\right\}$;

- $\epsilon=\epsilon_{r} \cup \epsilon_{a} /$ * 단위 업무와 역할간 할당 함수 */

- $\epsilon_{r}: \mathrm{A} \rightarrow \mathrm{R}$ 은 특정 단위 업무와 그 단위 업무의 실행을 담당하는 하나의 역할과의 매칭을 정의한 
단일 값 함수이며, $\epsilon_{a}: \mathrm{R} \rightarrow \mathrm{A}$ 는 특정 역할과 그 역할이 담당하는 다수의 단위 업무와의 매칭을 정의한 다중 값 함수이다.

- $\pi=\pi_{c} \cup \pi_{r} /$ 역할과 수행자간 할당 함수 */

- $\pi_{c}: \mathrm{R} \rightarrow \mathrm{P}$ 은 특정 역할과 그 역할에 배정된 다 수의 수행자와의 매칭을 정의한 다중 값 함수이 며, $\pi_{r}: \mathrm{P} \rightarrow \mathrm{R}$ 는 특정 수행자와 그 수행자가 속 한 다수의 역할과의 매칭을 정의한 다중 값 함수 이다.

아래 (그림 2)는 조직 관점의 ICN 워크플로우 모델에 대한 예제를 나타낸다. (그림 2)의 왼쪽은 단위 업무들과 이들간의 제어 흐름을 가시적으로 표현한 것이며, 오른 쪽에는 단위 업무와 역할, 수행자간의 할당 관계를 정의 한 것이다. 그러므로 (그림 2)의 워크플로우 모델은 16 개 의 단위 업무와 12 명의 수행자를 포함하고 있다.

\begin{tabular}{|l|l|l|}
\hline & $\alpha_{1}$ & $\phi_{2}, \phi_{3}, \phi_{6}, \phi_{7}$ \\
\hline$\alpha_{2}$ & $\phi_{1}, \phi_{11}$ \\
\hline$\alpha_{3}$ & $\phi_{3}, \phi_{6}, \phi_{11}$ \\
\hline$\alpha_{4}$ & $\phi_{4}, \phi_{5}$ \\
\hline$\alpha_{5}$ & $\phi_{8}, \phi_{11}$ \\
\hline$\alpha_{6}$ & $\phi_{4}, \phi_{5}, \phi_{9}$ \\
\hline$\alpha_{7}$ & $\phi_{3}$ \\
\hline \multirow{2}{*}{$\alpha_{2}$} \\
\hdashline
\end{tabular}

(그림 2) 조직 관점의 ICN 워크플로우 모델 예제

(Figure 2) The example of ICN workflow model on organizational-perspective

\section{2 업무-수행자 소속성 네트워크 모델}

앞서 3.1절에서 정의했듯이, 조직 관점의 ICN 워크플 로우 모델은 제어 흐름을 나타내는 일련의 단위 업무들 과 단위 업무와 역할간의 할당 정보와 역할과 수행자간 의 할당 정보를 통해 정의된다. 그러므로 업무-수행자 소 속성 네트워크 모델은 워크플로우 모델(비즈니스 프로세 스)에 정의된 업무들과 수행자들과의 소속 관계를 나타
내는 소셜 네트워크이며, 이를 정형적, 가시적으로 정의 한 형태이다[13-15].

업무-수행자 소속성 네트워크 모델은 정형적으로 $\Lambda=(\sigma, \psi)$ 와 같이 2 개의 튜플로 표현되며, 각각의 정의 는 다음과 같다. 여기서 $\mathbf{A}$ 는 단위 업무들의 집합이고, $\mathbf{P}$ 는 수행자들의 집합, $\mathrm{V}$ 는 링크 강도치의 집합, $\mathbf{E p}$ 는 수 행자와 단위 업무간의 링크 집합, $\mathbf{E a}$ 는 단위 업무와 수 행자간의 링크 집합을 말한다.

[정의 2] 업무-수행자 소속성 네트워크 모델의 정의 $\Lambda=$ [ function $(\sigma, \psi), \operatorname{set}(\mathbf{A}, \mathbf{P}, \mathbf{V}, \mathbf{E p}, \mathbf{E a})]$

- 단위 업무들의 집합, $\mathbf{A}=\left\{\alpha_{1}, \ldots, \alpha_{n}\right\}$;

- 수행자들의 집합, $\mathbf{P}=\left\{\phi_{1}, \ldots, \phi_{k}\right\}$;

- 링크강도치의 집합, $\mathbf{V}$;

- 수행자와 단위 업무간의 링크 집합, $\mathbf{E p}=\mathbf{P} \times \mathbf{A}=$ $\left\{\left(\phi_{i}, \alpha_{j}\right), 1 \leq j \leq n ; 1 \leq i \leq k\right\} ;$

- 단위 업무와 수행자간의 링크 집합, $\mathbf{E a}=\mathbf{A} \times \mathbf{P}=$ $\left\{\left(\alpha_{i}, \phi_{j}\right), 1 \leq i \leq n ; 1 \leq j \leq k\right\}$;

- $\sigma=\sigma_{p} \cup \sigma_{v} /$ * 업무 소속 관계 함수 */

- $\sigma_{p}: \mathrm{C} \rightarrow \mathrm{A}$ 는 특정 수행자와 그 수행자가 소속 된 다수의 단위 업무와의 매칭을 정의한 다중 값 함수이며, $\sigma_{v}: \mathrm{E}_{\mathrm{p}} \rightarrow \mathrm{V}$ 는 특정 수행자와 그 수행 자가 소속된 특정 단위 업무 쌍 $\left(\phi_{i}, \alpha_{j}\right)$ 과 그에 대 한 링크 강도치와의 매칭을 정의한 단일 값 함수 이다.

- $\psi=\psi_{a} \cup \psi_{v} / *$ 수행자 참여 관계 함수 */

- $\psi_{a}: \mathrm{A} \rightarrow \mathrm{P}$ 는 특정 단위 업무와 그 단위 업무에 참여하는 다수의 수행자와의 매칭을 정의한 다중 값 함수이며, $\psi_{v}: \mathrm{E}_{\mathrm{a}} \rightarrow \mathrm{V}$ 는 특정 단위 업무와 그 단위 업무에 참여하는 특정 수행자 쌍 $\left(\alpha_{i}, \phi_{j}\right)$ 과 그에 대한 링크 강도치와의 매칭을 정의한 단 일 값 함수이다.

위의 정의에서 단위 업무와 수행자간의 연결 강도는 그들의 링크 강도치 값에 의해 측정된다. 그러므로 업무수행자 소속성 네트워크 모델은 링크 강도치의 종류에 따라 이진(binary) 업무-수행자 소속성 네트워크 모델, 비 이진(non-binary) 업무-수행자 소속성 네트워크 모델로 나 뉘어 진다. 이진 업무-수행자 소속성 네트워크 모델의 경 우 단위 업무와 수행자간의 연결 강도는 이진 값(0 또는 1)을 가지며, 비이진 업무-수행자 소속성 네트워크 모델 은 확률, 강도, 빈도 등등의 다양한 형태의 값을 적용할 수 있다. 또한 가시적 표기법은 수행자를 정육각형으로, 


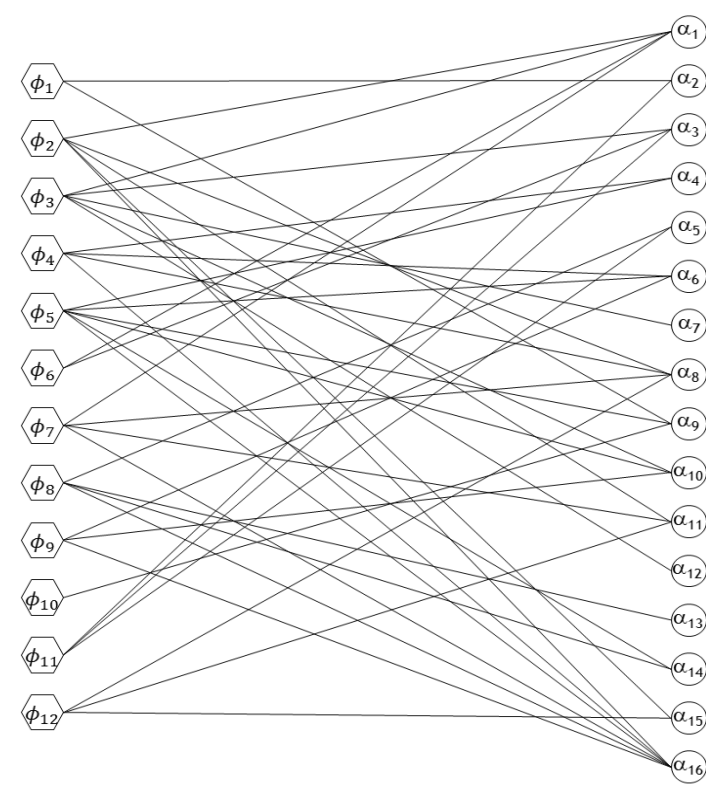

(그림 3) 발견된 업무-수행자 소속성 네트워크 모델의 가시화 (Figure 3) A representation of discovered activity-performer affiliation networks

단위 업무는 원으로 표기하며, 그들간의 연결 관계는 직 선 또는 곡선의 화살표로 표기한다. (그림 3)은 예제 워크 플로우 모델을 입력으로, [16]에서 제안한 발견 알고리즘 에 의해 추출된 업무-수행자 소속성 네트워크 모델을 이 분 그래프 형태로 가시화한 것이다. 본 논문에서는 (그림
3)과 같이 업무와 수행자간의 연결 유무를 나타내는 이 진 업무-수행자 소속성 네트워크 모델을 예제로 하며, 이 들 간의 링크 강도치는 모두 1 의 값을 가진다.

발견된 업무-수행자 소속성 네트워크 모델에 대하여 대응분석을 적용하기 위해서는 다변량 자료로 구성된 분 할표와 같은 입력을 요구한다. 그러므로 [17]에서 제안한 업무-수행자 소속성 네트워크 모델에 대한 이분 행렬 생 성 알고리즘을 통해 업무-수행자 이분 행렬을 구할 수 있 으며, 이를 입력으로 하여 업무-수행자 대응분석을 할 수 있다. 업무-수행자 이분 행렬 $\mathbf{X}$ 는 다음과 같이 나타낼 수 있다.

$$
X=\left(\begin{array}{ll}
O & Z_{p} \\
Z_{a} & O
\end{array}\right)
$$

업무-수행자 이분 행렬 $X$ 는 업무, 수행자를 속성으로 가지는 대칭 행렬이며, 수행자 중심의 부분 행렬 $Z_{p}$ 와 $Z_{p}$ 의 전치 행렬인 업무 중심의 부분 행렬 $Z_{a}$ 로 구성되며, $O$ 는 모두 0 의 값을 갖는 부분 행렬이다. 아래의 (표 1)은 (그림 3)에 대한 업무-수행자 이분 행렬 $X$ 의 부분 행렬인 $Z_{p}$ 을 나타낸다. $Z_{p}$ 의 행은 12 명의 수행자로 구성되며, 열 은 16 개의 업무로 구성된다.

\section{4. 업무-수행자 대응분석}

대응분석(correspondence analysis)은 서로 다른 차원의

(표 1) 이분 행렬 $X$ 의 부분 행렬 $Z_{p}=\left[x_{i j}\right]_{12 \times 16}$

(Table 1) A submatrix $Z_{p}=\left[x_{i j}\right]_{12 \times 16}$ for bipartite matrix $X$

\begin{tabular}{|c|c|c|c|c|c|c|c|c|c|c|c|c|c|c|c|c|}
\hline & $\alpha_{1}$ & $\alpha_{2}$ & $\alpha_{3}$ & $\alpha_{4}$ & $\alpha_{5}$ & $\alpha_{6}$ & $\alpha_{7}$ & $\alpha_{8}$ & $\alpha_{9}$ & $\alpha_{10}$ & $\alpha_{11}$ & $\alpha_{12}$ & $\alpha_{13}$ & $\alpha_{14}$ & $\alpha_{15}$ & $\alpha_{16}$ \\
\hline$\phi_{1}$ & 0 & 1 & 0 & 0 & 0 & 0 & 0 & 0 & 1 & 0 & 0 & 0 & 0 & 0 & 0 & 0 \\
\hline$\phi_{2}$ & 1 & 0 & 0 & 0 & 0 & 0 & 0 & 1 & 0 & 0 & 1 & 0 & 0 & 0 & 1 & 1 \\
\hline$\phi_{3}$ & 1 & 0 & 1 & 0 & 0 & 0 & 1 & 0 & 0 & 1 & 0 & 1 & 0 & 0 & 0 & 0 \\
\hline$\phi_{4}$ & 0 & 0 & 0 & 1 & 0 & 1 & 0 & 1 & 0 & 0 & 0 & 0 & 0 & 0 & 0 & 1 \\
\hline$\phi_{5}$ & 0 & 0 & 0 & 1 & 0 & 1 & 0 & 0 & 1 & 1 & 0 & 0 & 0 & 1 & 0 & 1 \\
\hline$\phi_{6}$ & 1 & 0 & 1 & 0 & 0 & 0 & 0 & 0 & 0 & 0 & 0 & 0 & 0 & 0 & 0 & 0 \\
\hline$\phi_{7}$ & 1 & 0 & 0 & 0 & 0 & 0 & 0 & 1 & 0 & 0 & 1 & 0 & 0 & 0 & 0 & 1 \\
\hline$\phi_{8}$ & 0 & 0 & 0 & 0 & 1 & 0 & 0 & 0 & 0 & 0 & 0 & 0 & 1 & 1 & 0 & 1 \\
\hline$\phi_{9}$ & 0 & 0 & 0 & 0 & 0 & 1 & 0 & 0 & 0 & 1 & 0 & 0 & 0 & 0 & 0 & 1 \\
\hline$\phi_{10}$ & 0 & 0 & 0 & 0 & 0 & 0 & 0 & 0 & 1 & 0 & 0 & 0 & 0 & 0 & 0 & 0 \\
\hline$\phi_{11}$ & 0 & 1 & 1 & 0 & 1 & 0 & 0 & 0 & 0 & 0 & 0 & 0 & 0 & 0 & 0 & 0 \\
\hline$\phi_{12}$ & 0 & 0 & 0 & 0 & 0 & 0 & 0 & 1 & 0 & 0 & 1 & 0 & 0 & 0 & 1 & 0 \\
\hline
\end{tabular}




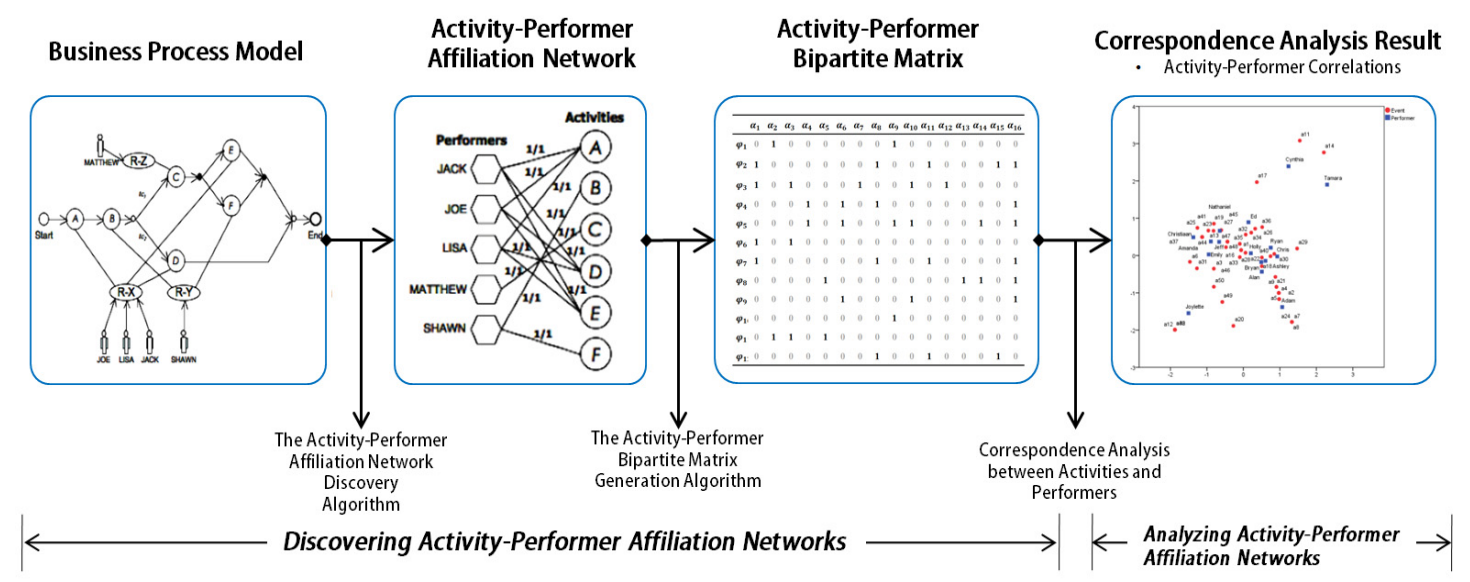

(그림 4) 업무-수행자 대응분석 프레임워크

(Figure 4) A framework for activity-performer correspondence analysis

자료들간의 상호 연관성을 2 차원의 평면에 요약하여 가 시화하기 위한 다변량 분석(multivariate analysis) 기법이 다[18]. 이는 주성분 분석(principle components analysis)과 개념적으로 비슷하나, 연속형 자료(continuous data)보다 는 주로 범주형 자료(categorical data)를 대상으로 하며, 자료간의 거리는 유클리드 거리(Euclidean distance) 또는 카이제곱 거리(chi-square distance)로 계산한다.

본 논문에서는 BPM 기반 조직의 업무와 수행자간의 대응분석을 다루기 때문에, 일반적인 분할표의 자료가 아닌, 앞서 3장에서 설명한 업무-수행자 소속성 네트워크 발견 과정의 최종 출력 형태인 업무-수행자 이분 행렬 [17]의 자료를 대상으로 분석을 실시한다. 따라서 본 장 에서는 업무-수행자 소속성 네트워크 모델의 발견부터 대응분석으로 이어지는 전체 과정을 나타내는 대응분석 프레임워크에 대해 설명하며, 세부적인 업무-수행자 대 응분석 과정에 대해 서술한다.

\section{1 업무-수행자 대응분석 프레임워크}

아래의 (그림 4)는 BPM 기반 조직의 업무-수행자 대 응분석의 전체 수행 과정을 나타내는 프레임워크이다. 업무-수행자 대응분석 과정은 크게 비즈니스 프로세스를 나타내는 워크플로우 모델로부터 업무-수행자 소속성 네 트워크 모델을 발견하는 과정과 발견된 업무-수행자 소 속성 네트워크 모델에 대한 이분 행렬을 생성하고, 이를 입력으로 하여 업무-수행자 대응분석을 수행 하는 과정 으로 나뉘어진다. 업무-수행자 대응분석의 세부적인 수
행 단계는 다음과 같다.

1) 비즈니스 프로세스 모델에 정의되어 있는 업무와 역 할간의 할당관계와 역할과 수행자간의 할당관계를 바 탕으로 [16]에서 제안된 발견 알고리즘을 통해 업무수행자 소속성 네트워크 모델을 발견한다.

2) 발견된 업무-수행자 소속성 네트워크 모델의 대응분 석을 수행하기 위해, 대응분석의 입력 형태인 업무-수 행자 이분 행렬[17]을 생성한다. 이분 행렬은 업무와 수행자, 두 가지의 원소 타입으로 구성되며, 원소 값 에 따른 행렬 타입은 이진 행렬(binary matrix), 비이진 행렬(non-binary matrix)로 나뉜다. 본 논문에서는 업무 와 수행자간의 연결 관계의 유무를 나타내는 이진 행 렬 형태의 업무-수행자 이분 행렬에 대한 대응분석을 수행한다.

3) 생성된 업무-수행자 이분 행렬을 입력으로 하여 대응 분석을 수행한다. 대응분석은 업무-수행자 이분 행렬 에 대한 대응 행렬(correspondence matrix)을 구하고, 각각의 행과 열에 대한 프로파일 벡터와 가중치, 프로 파일 벡터간의 가중 유클리드 거리를 계산하고, 특이 값 분해를 통한 차원 축소를 통해, 최종적으로 2차원 평면상에 가시화한다.

\section{2 업무-수행자 대응분석}

대응분석의 주목적은 범주형 자료의 연관 관계를 이 차원 공간상에 나타내어 행 범주와 열 범주간 대응 양상 
을 탐색적으로 살펴보는 것이다. 분석 결과인 이차원 공 간에서 행과 열의 범주에 속하는 자료들은 서로 유사한 정도에 따라 상대적으로 근접하게 위치하여 군집을 형성 하므로, 자료간의 대응 관계를 파악할 수가 있다. 그러므 로 BPM 기반 조직의 업무-수행자 대응분석은 비즈니스 프로세스 모델에 정의되어 있는 업무들과 수행자들간의 연관 관계를 살펴보기 위함이며, 이차원 평면으로 표현 되는 대응분석의 결과에서 업무들과 수행자들을 나타내 는 각각의 좌표점간의 거리가 가까울수록 두 개의 속성 이 밀접하게 연관되어 있다고 해석할 수 있다. 이러한 대 응분석의 결과에 영향을 미치는 요소들은 다음과 같다.

- 수행자들간의 업무 협업 관계: 특정 업무에 공통적으 로 소속되는 두 수행자 사이에는 업무에 관련된 협업 관계가 존재한다고 가정하며, 두 수행자 사이에 업무 협업 관계의 빈도수가 높을수록 두 수행자를 나타내 는 좌표점간의 거리가 가까워진다.

- 업무들간의 수행자 공유 관계: 특정 수행자가 공통적 으로 참여하고 있는 두 업무 사이에는 특정 수행자를 공유한다고 말하며, 많은 수행자를 공유할수록, 두 업무를 나타내는 좌표점간의 거리가 가까워진다.

- 업무와 수행자간 소속관계: 특정 수행자가 특정 업무 에 소속(또는 참여)될 때, 두 속성을 나타내는 좌표점 간의 거리가 가까워진다.

업무-수행자 대응분석의 세부적인 계산 과정은 먼저
대응분석에 입력 형태인 업무-수행자 이분 행렬 $X$ 에 대 한 대응 행렬 $P$ 를 구하고, 각각의 행과 열에 대한 프로 파일과 가중치(mass), 그리고 프로파일 벡터간의 가중 유 클리드 거리(weighted Euclidean distance)를 계산한 뒤, 특 이값 분해(singular value decomposition, SVD)에 의한 차 원 축소(dimension reduction)를 거쳐 2차원 평면상에 업 무, 수행자에 해당하는 좌표 점들을 가시화하는 과정으 로 구성된다.

대응 행렬 $P$ 는 업무-수행자 이분 행렬 $X$ 의 부분 행렬 $Z_{p}$ 를 구성하는 각각의 원소 값 $x_{i j}$ 에 대한 대응 확률 $\left(p_{i j}\right)$ 을 원소 값으로 가지는 행렬이며, 이에 대한 수식은 다음 과 같다.

$$
\begin{gathered}
n=\sum_{i=1}^{g} \sum_{j=1}^{h} x_{i j} \\
p_{i j}=\frac{x_{i j}}{n}
\end{gathered}
$$

수식 2 와 같이 $g$ 명의 수행자와 $h$ 개의 업무로 구성되 는 $X$ 의 부분 행렬 $Z_{p}$ 의 모든 원소 값의 총합을 $n$ 이라고 하면, 대응 행렬 $P$ 의 원소 값 $p_{i j}$ 는 수식 3 과 같이 부분 행렬 $Z_{p}$ 의 단위원소 $x_{i j}$ 를 총합 $n$ 으로 나눈 값이다.

(표 2)는 3장에서 예시된 (표 1)의 업무-수행자 이분 행 렬 $X$ 의 부분 행렬 $Z_{p}$ 에 대한 대응 행렬 $P$ 를 나타낸다. $Z_{p}$ 의 모든 원소 값의 총합은 42 이며, 이 값은 업무-수행

(표 2) 업무-수행자 이분 행렬 $X$ 에 대한 대응 행렬 $P=\left[p_{i j}\right]_{12 \times 16}$

(Table 2) A correspondence matrix $P=\left[p_{i j}\right]_{12 \times 16}$ for the activity-performer bipartite matrix $X$

\begin{tabular}{cccccccccccccccccc}
\hline & $\alpha_{1}$ & $\alpha_{2}$ & $\alpha_{3}$ & $\alpha_{4}$ & $\alpha_{5}$ & $\alpha_{6}$ & $\alpha_{7}$ & $\alpha_{8}$ & $\alpha_{9}$ & $\alpha_{10}$ & $\alpha_{11}$ & $\alpha_{12}$ & $\alpha_{13}$ & $\alpha_{14}$ & $\alpha_{15}$ & $\alpha_{16}$ & $p_{i+}$ \\
\hline$\phi_{1}$ & - & - & .0238 & - & - & - & - & - & .0238 & - & - & - & - & - & - & - & .0476 \\
$\phi_{2}$ & .0238 & - & - & - & - & - & - & .0238 & - & - & .0238 & - & - & - & .0238 & .0238 & .1190 \\
$\phi_{3}$ & .0238 & - & .0238 & - & - & - & .0238 & - & - & .0238 & - & .0238 & - & - & - & - & .1190 \\
$\phi_{4}$ & - & - & - & .0238 & - & .0238 & - & .0238 & - & - & - & - & - & - & - & .0238 & .0952 \\
$\phi_{5}$ & - & - & - & .0238 & - & .0238 & - & - & .0238 & .0238 & - & - & - & .0238 & - & .0238 & .1428 \\
$\phi_{6}$ & .0238 & - & .0238 & - & - & - & - & - & - & - & - & - & - & - & - & - & .0476 \\
$\phi_{7}$ & .0238 & - & - & - & - & - & - & .0238 & - & - & .0238 & - & - & - & - & .0238 & .0952 \\
$\phi_{8}$ & - & - & - & - & .0238 & - & - & - & - & - & - & - & .0238 & .0238 & - & .0238 & .0952 \\
$\phi_{9}$ & - & - & - & - & - & .0238 & - & - & - & .0238 & - & - & - & - & - & .0238 & .0714 \\
$\phi_{10}$ & - & - & - & - & - & - & - & - & .0238 & - & - & - & - & - & - & - & .0238 \\
$\phi_{11}$ & - & .0238 & .0238 & - & .0238 & - & - & - & - & - & - & - & - & - & - & - & .0714 \\
$\phi_{12}$ & - & - & - & - & - & - & - & .0238 & - & - & .0238 & - & - & - & .0238 & - & .0714 \\
$p_{+j}$ & .0952 & .0476 & .0714 & .0476 & .0476 & .0714 & .0238 & .0952 & .0714 & .0714 & .0714 & .0238 & .0238 & .0476 & .0476 & .1428 & \\
\hline
\end{tabular}


자 소속성 네트워크에서 업무와 수행자간의 모든 연결 관계 수를 의미한다. 본 논문에서의 업무-수행자 이분 행 렬은 업무와 수행자간의 연결 관계의 유무를 나타내는 이진 행렬이므로, 대응 행렬 $P$ 의 모든 원소 값 $p_{i j}$ 는 $1 / 42$ $(0.0238)$ 또는 0 의 값을 가진다. 여기서 $p_{i+}$ 는 대응 행렬 $P$ 의 각각의 행(수행자)에 대한 가중치를 나타내며 $i$ 번째 행에 속하는 모든 원소 값의 합으로 구한다. 또한 $p_{+j}$ 는 대응 행렬 $P$ 의 각각의 열(업무)에 대한 가중치를 나타내며, $j$ 번째 열에 속하는 모든 원소 값의 합으로 구한다. 대응 행렬과 각각의 행과 열에 대한 가중치가 계산되면, 다음 수식과 같은 행 프로파일과 열 프로파일을 구할 수 있다.

$$
\begin{aligned}
& r_{i}=\left(p_{i 1} / p_{i+}, \ldots, p_{i h} / p_{i+}\right) \\
& c_{j}=\left(p_{1 j} / p_{+j}, \ldots, p_{g j} / p_{+j}\right)
\end{aligned}
$$

$g$ 개의 업무에 대한 행 프로파일 $r_{1}, \ldots, r_{g}$ 는 $h$ 차원의 가중 유클리드 공간(weighted Euclidean space)에서의 좌표 점으로 나타내며, 좌표점간의 거리를 구하는 수식[16]은 다음 수식 5 와 같다. 이와 반대로 열 프로파일 $c_{1}, \ldots, c_{h}$ 는 $g$ 차원의 가중 유클리드 공간에서의 좌표점으로 나타 내며, 수식 6 은 행 프로파일 좌표점간의 거리를 구하는 수식을 나타낸다.

$$
\begin{aligned}
& d\left(r_{a}, r_{b}\right)=\sqrt{\sum_{j=1}^{h}\left(\frac{p_{a j}}{p_{a+}}-\frac{p_{b j}}{p_{b+}}\right)^{2} / p_{+j}} \\
& d\left(c_{a}, c_{b}\right)=\sqrt{\sum_{i=1}^{g}\left(\frac{p_{i a}}{p_{+a}}-\frac{p_{i b}}{p_{+b}}\right)^{2} / p_{i+}}
\end{aligned}
$$

일반적으로 대응분석은 다차원 공간의 행과 열 프로 파일의 좌표값 $\left(r_{i}, c_{j}\right)$ 과 프로파일에 할당된 가중치 $\left(p_{i+}, p_{+j}\right)$, 그리고 좌표점간의 가중 유클리드 거리(또는 카이 제곱 거리)를 요소로 하며, 가중 유클리드 공간에서 의 행 좌표점 $\left(r_{1}, \ldots, r_{g}\right)$ 과 열 좌표점 $\left(c_{1}, \ldots, c_{h}\right)$ 을 2 차원 평면상에 동시에 나타내어 이들의 관계를 탐구하는 것이 목적이며, 이를 위한 차원축소 과정은 특이값 분해 방법 (singular value decomposition)을 이용한다[16].

위의 (그림 5)는 예제 비즈니스 프로세스 모델에 대한 업무-수행자 대응분석 결과를 가시화한 것이다. 분석 결 과를 살펴보면 예제 비즈니스 프로세스 모델의 업무들과 수행자들의 경우, 대부분 특정 업무들 또는 수행자들간

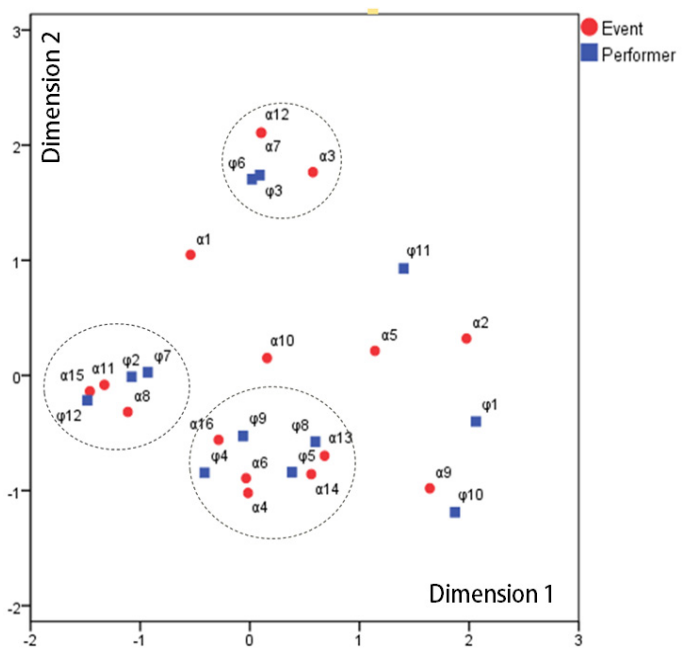

(그림 5) 업무-수행자 대응분석 결과

(Figure 5) The result of activity-performer correspondence analysis

에 서로 밀접한 연관성을 가지며 군집을 형성하고 있는 것을 볼 수 있는데, 여기서 밀접한 연관성은 앞서 대응분 석 결과에 영향을 미치는 요소로 정의한 업무 협업 관계, 수행자 공유 관계, 업무와 수행자의 소속 관계에 의해 대 응분석 결과인 2 차원 평면상에 이들을 나타내는 점들이 상대적으로 가깝게 위치하는 것으로 표현된다. 특히 수 행자 그룹 $\left(\phi_{2}, \phi_{7}, \phi_{12}\right)$ 은 업무 그룹 $\left(\alpha_{8}, \alpha_{11}, \alpha_{15}\right)$ 에 공통 적으로 소속되기 때문에 이들간의 협업 관계 강도가 크 다고 해석할 수 있으며, 반대로 업무 그룹은 수행자 그룹 을 공통적으로 공유하기 때문에 업무들간에 관련성이 크 다고 할 수 있다. 이외에도 수행자 그룹 $\left(\phi_{3}, \phi_{6}\right)$ 과 업무 그룹 $\left(\alpha_{3}, \quad \alpha_{7}, \alpha_{12}\right)$ 으로 이루어진 군집(차원1: 0.020 0.575 , 차원2: $1.705 \sim 2.108)$ 과 수행자 그룹 $\left(\phi_{4}, \phi_{5}, \phi_{8}\right.$, $\left.\phi_{9}\right)$ 과 업무 그룹 $\left(\alpha_{4}, \alpha_{6}, \alpha_{13}, \alpha_{14}, \alpha_{16}\right)$ 으로 이루어진 군 집(차원1: $-0.413 \sim 0.682$, 차원2: $-1.021 \sim-0.526$ ) 등이 있으 며, 나머지 수행자 그룹 $\left(\phi_{1}, \phi_{10}, \phi_{11}\right)$ 과 업무 그룹 $\left(\alpha_{1}, \alpha_{2}\right.$, $\left.\alpha_{5}, \alpha_{9}, \alpha_{10}\right)$ 은 어느 군집에도 속하지 않으며, 상대적으로 다른 개체(업무, 수행자)들과의 연관성을 적게 가진다고 볼 수 있다. 결론적으로 업무와 수행자간의 소속 관계, 업무간의 수행자 공유 관계, 수행자간의 업무 협업 관계 등은 업무-수행자 소속성 네트워크 발견 단계에서 생성 되는 업무-수행자 이분 행렬과 이로부터 얻을 수 있는 업 무 협업 행렬(actor co-membership matrix)와 수행자 공유 행렬(event overlap matrix)를 통해 각각 수치화된 결과를 
얻을 수 있으나, 대응분석은 이러한 요소들을 동시에 반 영하여 2차원 평면상에 나타내므로, 종합적으로 개체들 간의 연관 관계를 탐색적으로 살펴볼 수 있는 장점을 가 지고 있다. 그러므로 비즈니스 프로세스에 정의된 업무 와 수행자간 대응분석을 통해 서로 상이한 타입인 두 개 체간의 연관 관계를 고려하여 좀더 효과적으로 비즈니스 프로세스 모델을 설계할 수 있도록 도움을 줄 수 있다.

\section{5. 결론 및 향후 연구}

본 논문에서는 $\mathrm{BPI}$ 를 위한 새로운 분석 방법으로서, 비즈니스 프로세스 모델에 정의되어 있는 업무와 수행자 간의 대응분석을 통해 이들간의 연관 관계를 분석하는 과정에 대하여 기술하였다. 먼저 업무-수행자 소속성 네 트워크 발견과 대응분석 과정을 나타내는 업무-수행자 대응분석 프레임워크를 제안하였고, 업무-수행자 이분 행렬로부터 대응분석을 수행하는 과정에 대해 설명하였 다. 또한 이를 바탕으로 특이값 분해 과정을 통해 최종적 으로 2 차원 평면상으로 나타나는 대응분석 결과를 통해 업무와 수행자간의 소속 관계, 수행자간의 업무 협업 관 계, 업무간의 수행자 공유 관계 등을 효과적, 탐색적으로 살펴볼 수 있는 가능성을 보였다. 이것을 통해 비즈니스 프로세스에 정의된 업무와 수행자간의 연관 관계를 고려 한 비즈니스 프로세스 설계의 효율성을 제고할 수 있다 고 기대된다. 그러나 본 논문에서는 정의 시점의 비즈니 스 프로세스 모델을 예제로 하였고, 이진 형태의 이분 행 렬(업무와 수행자간의 연결 유무만을 나타냄)을 입력으 로 하였다. 그러므로 대응분석 결과가 조금 더 비즈니스 프로세스 기반 조직의 업무와 수행자간 연관 관계를 반 영하고, 비즈니스 프로세스 설계에 더 효과적인 정보를 제공하기 위해서는 비즈니스 프로세스 실행 시점에 생성 되는 로그 데이터 분석을 통한 업무-수행자 소속성 네트 워크 재발견 과정과 이진 형태가 아닌 빈도 또는 가중치 를 가지는 비이진 형태의 이분 행렬에 대한 대응분석이 요구되며 이에 대한 향후 연구가 필요하다.

\section{참 고 문 헌(Reference)}

[1] F. Leymann, D. Roller, Production Workflow: Concepts and Techniques, Prentice Hall PTR, 1999.

[2] C. A. Ellis, G. J. Nutt, "Office Information Systems and Computer Science," ACM Computing Surveys, Vol. 12, No. 1, pp.27-60, 1980.
[3] K. Kim, "Workflow Technology П: Workflow Management Technology and Business Process Management Technology," TTA Journal, No. 87, pp.120-133, 2003.

[4] K. Kim, "Business Process Management System," Korea Information Processing Society Review, Vol. 12, No, 3, pp.45-56, 2005.

[5] W. M. P. van der Aalst, A. J. M. M. Weijters, "Process Mining: A Research Agenda," Journal of Computers in Industry, Vol. 53, No. 3, pp.231-244, 2004.

[6] M. Park, K. Kim, "Control-path Oriented Workflow Intelligence Analyses," Journal of Information Science and Engineering, Vol. 24, No.2, pp.343-359, 2008.

[7] M. Park, K. Kim, "A Workflow Evnet Logging Mechanism and Its Implications on Quality of Workflows," Journal of Information Science and Engineering, Vol. 26, No. 5, pp.1817-1830, 2010.

[8] D. Grigori, et al., "Business Process Intelligence," Journal of Computer in Industry, Vol. 53, No. 3, pp.321-343, 2004.

[9] J. Schiefer, et al., "Process Information Factory: A Data Management Approach for Enhancing Business Process Intelligence," Proceedings of the IEEE International Conference on e-Commerce Technology, pp.162-169, 2004.

[10] W. Tan, et al., "A Business Process Intelligence System for Enterprise Process Performance Management," IEEE Transactions on Systems, Man, and Cybernetics, Part C: Applications and Reviews, Vol. 38, No. 6, pp.745-756, 2008.

[11] K. Faust, "Centrality in Affiliation Networks," Journal of Social Networks, Vol. 19, No. 2, pp.157-191, 1997.

[12] S. P. Borgatti, D. S. Halgin, "Analyzing Affiliation Networks," The Sage Handbook of Social Network Analysis, pp.417-433, 2010.

[13] H. Kim, H. Ahn, K. Kim, "A Workflow Affiliation Network Discovery Algorithm," ICIC Express Letters, Vol. 6, No. 3, pp.765-770, 2012.

[14] K. Kim, "Discovering Activity-Performer Affiliation Knowledge on ICN-based Workflow Models," 
Journal of Information Science and Engineering, Vol.

29, No. 1, pp.79-97, 2013.

[15] H. Ahn, K. Kim, "An Activity-Performer Bipartite Matrix Generation Algorithm for Analyzing Workflow-supported Human-Resource Affiliations," Journal of Korean Society for Internet Information (accepted), 2013.

[16] A. Agresti, Categorical Data Analysis Introduction, Translated by K. Jeong, Y. Choi, 2009.

[17] W. M. P. van der Aalst, et al., "Discovering Social
Networks from Event Logs," Journal of Computer Supported Cooperative Work, Vol. 14, No. 6, pp. 549-593, 2005.

[18] K. Kim, "A Workflow-based Social Network Discovery and Analysis System," Proceedings of the 1st International Symposium on Data-driven Process Discovery and Analysis, pp. 163-176, 2011.

[19] K. Kim, C.A. Ellis, "ICN-Based Workflow Model and Its Advances," Handbook of Research on Business Process Modelling, pp.34-54, 2009.

\section{저 자 소 개}

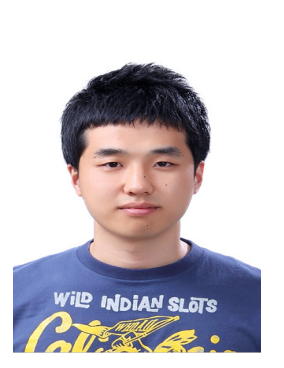

\section{안 현}

2011년 경기대학교 컴퓨터과학과(학사)

2013년 경기대학교 일반대학원 컴퓨터과학과(석사)

2013년 현재 경기대학교 일반대학원 컴퓨터과학과(박사 과정)

관심분야 : 워크플로위비피엠 기술, 비즈니스 프로세스 인텔리전스

E-mail : hahn@kgu.ac.kr

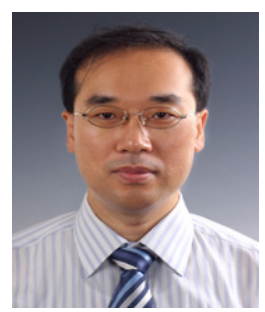

\section{박 천 건}

1993년 경기대학교 수학과(학사)

1995년 중앙대학교 대학원 응용통계학과(석사)

2003년 Texas A\&M University 대학원 통계학과(박사)

2010년 현재 경기대학교 수학과 조교수

관심분야 : 베이지안 추론, 웨이블렛

E-mail : cgpark@kgu.ac.kr

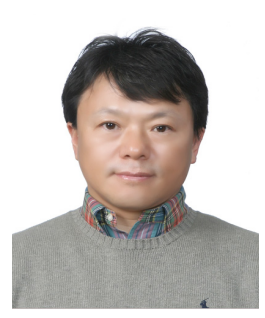

\section{김 광 훈}

1984년 경기대학교 전자계산학과(학사)

1986년 중앙대학교 전자계산학과(석사)

1994년 University of Colorado at Boulder 대학원 컴퓨터과학과(석사)

1998년 University of Colorado at Boulder 대학원 컴퓨터과학과(박사)

1998년 현재 경기대학교 컴퓨터과학과 교수

관심분야 : 워크플로위비피엠 기술, RFID/USN 미들웨어 기술, Collaboration Technology

E-mail: kwang@kgu.ac.kr 